\title{
Non-invasive internal morphological examination of epizoic zoanthids utilizing CT scanners
}

Received: 6 January 2009/Accepted: 17 February 2009/Published online: 12 March 2009

(C) Springer-Verlag 2009
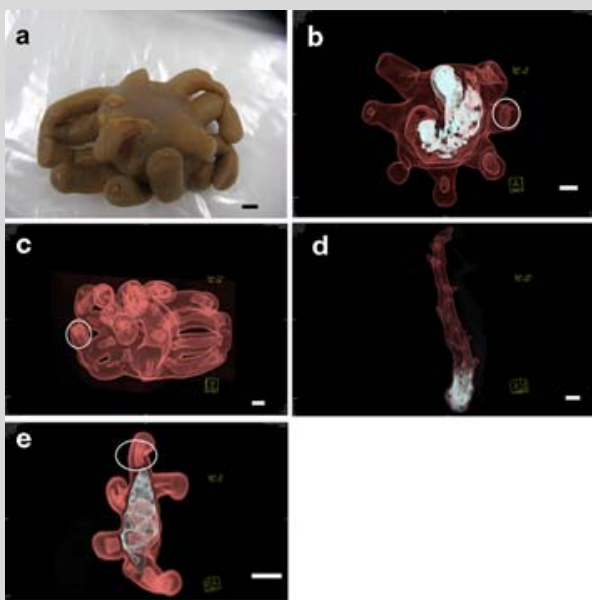

Fig. 1 Epizoanthus spp. associated with pagurid crabs (a-c), eunicid worm tubes (d), and molluscs (e). Specimens in b-e were examined using a computer tomography (CT) scanner (all scale

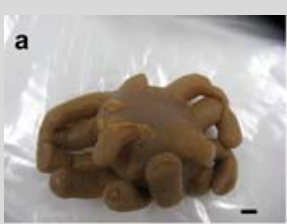
bars $=1 \mathrm{~cm}$ )

Epizoic zoanthids are found from coral reef communities (e.g., Acrozoanthus) to the deep sea (Epizoanthus spp.) (Muirhead et al. 1986; Ates 2003). While often the substrate identity is obvious, in other associations only the zoanthid is visible from the outside, making invasive examination the only method to determine if a substrate is present, and what or where the substrate is within the zoanthid. While invasive sampling is often very easy to perform, for rare, unknown, or type specimens, this may not be a desirable option. Zoanthid internal examination is also made difficult by their uptake of sand and detritus to help form their structure.

In an attempt to solve these problems, several Epizoanthus spp.

(Fig. 1; all scale bars $=1 \mathrm{~cm}$ ) associated with pagurid crabs (Fig. 1a, b, c), eunicid worm tubes (Fig. 1d), and molluscs (Fig. 1e) were examined using a Somatom Spirit (Siemens Co., Tokyo, Japan) computer tomography (CT) scanner at Okinawa Churaumi Aquarium, Motobu, Japan. Results showed substrates clearly visible in some specimens (eunicid worm tube in Fig. 1d, shell in Fig. 1e), while some specimens had no apparent substrate except for a pagurid crab (white section in Fig. 1b, also Fig. 1c).

Additionally, diagnostic taxonomic characters such as tentacles and mesenterial areas were also often distinguishable (e.g., circles in Fig. 1b, c, e), as was potential biomineralization (white sections in Fig. 1d).

As many CT scanners are designed to examine small animals, this method is not only potentially applicable to valuable specimens but also to many marine invertebrates with difficult to examine morphologies, such as sponges or octocorals and their spicule arrangement. Future examinations of zoanthids would be well served by imaging the interior morphology of specimens using high-resolution CT scanners. CT scanner technology has recently begun to be applied to biological specimens (e.g., DigiMorph project at the University of Texas), and undoubtedly the use of such technology in morphological examinations will become more commonplace in the future as technology advances.

\section{References}

Ates RML (2003) A preliminary review of zoanthid-hermit crab symbioses (Cnidaria; Zoantharia/Crustacea, Paguridea). Zool Verh Leiden 345:41-48

Muirhead A, Tyler PA, Thurston MH (1986) Reproductive biology and growth of the genus Epizoanthus (Zoanthidea) from the north-east Atlantic. J Mar Biol Assoc UK 66:131-143

J. D. Reimer $(\bowtie)$

Rising Star Program, University of the Ryukyus, 1 Senbaru, Nishihara, Okinawa 903-0213, Japan

e-mail: jreimer@sci.u-ryukyu.ac.jp

J. D. Reimer

Research Program for Marine Biology and Ecology, Extremobiosphere Research Center, Japan Agency for Marine-Earth Science and Technology (JAMSTEC), 2-15 Natsushima, Yokosuka, Kanagawa 237-0061, Japan

F. Sinniger

Department of Chemistry, Biology and Marine Science, Faculty of Science, University of the Ryukyus, 1 Senbaru, Nishihara, Okinawa 903-0213, Japan

M. Nonaka $\cdot$ S. Uchida

Okinawa Churaumi Aquarium, 424 Ishikawa, Motobu, Okinawa 905-0206, Japan

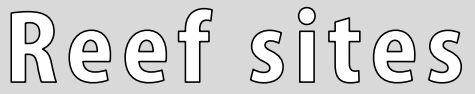

Coral Reefs (2009) 28:621

DOI $10.1007 / \mathrm{s} 00338-009-0487-7$ 